\title{
Reseña
}

\section{Las teorías contemporáneas del derecho como mapa teórico. Reflexiones desde las visiones internas y externas del derecho}

\author{
Reseña de: Jorge González Jácome y \\ Nicolás Parra Herrera (eds.), \\ Teorías contemporáneas del derecho, \\ Bogotá, Legis, 2021, 343 p.
}

Daniela Neira Márquez* 
El libro pretende hacer una representación simbólica de algunos rasgos y tendencias de la discusión teórica sobre el derecho que se presentan en Colombia. La idea de los editores es hacer un mapa para que el lector pueda, desde la filosofía y teoría del derecho, hacer un ejercicio teórico sobre esta disciplina y sus principales problemáticas.

Así mismo, el trabajo presentado pretende comprender las reflexiones teóricas que han hecho algunos académicos que han enseñado teoría jurídica y filosofía del derecho y de la política en la última década. En particular, con posterioridad a la expedición de la Constitución Política de 1991 en Colombia, se produjo una complejización en temas como la democracia y el desacuerdo, el derecho y la sociedad, la tecnificación de la decisión judicial, la deconstrucción y la relación entre el lenguaje y el derecho, entre otros.

Por lo tanto, más allá de dar respuestas exactas a cada una de las problemáticas, el texto aspira a brindar un bosquejo del terreno. Con este panorama inicial, tanto estudiantes como profesionales y practicantes del derecho y otras disciplinas podrán tener una idea de lo que se hace en estos campos de las ciencias jurídicas. A partir de lo planteado, dicen los editores, podrá iniciarse un ejercicio de lectura dialógico, en donde más que respuestas concretas, el lector conseguirá plantearse interrogantes y discusiones por resolver.

El libro tiene 12 capítulos escritos por distintos autores, profesores de Filosofía y Teoría del Derecho que, para hacer este ejercicio, eligieron al teórico más influyente en su trabajo. En cada uno de los capítulos, los escritores hacen énfasis en un aspecto central de la teoría de los autores escogidos. En la parte final de los textos, los autores plantearon unas reflexiones sobre los impactos que los pensamientos de los teóricos podían tener en las discusiones contemporáneas, particularmente en Colombia.

Para comprender el libro proponemos al lector abordar su análisis de la siguiente manera: por un lado, identificar los teóricos que plantean sus tesis desde una visión interna del derecho. Por el otro, identificar a los que plantean sus tesis desde una visión externa del derecho. Lo anterior, porque uno de los debates más actuales del constitucionalismo latinoamericano, y en concreto del constitucionalismo colombiano, es la relación que existe entre democracias y adjudicación judicial. Constantemente, como profesores y estudiantes del derecho, así como abogados, estamos directa o indirectamente preguntándonos qué debe prevalecer en una democracia constitucional; en estos casos vemos cómo la balanza entre democracia y constitucionalismo se inclina de un lado $\mathrm{u}$ otro en las discusiones tanto de los filósofos o teóricos del derecho como en las de los magistrados de las cortes constitucionales.

La invitación para todo el que lea Teorías contemporáneas del derecho es a que analice y entienda a cada uno de los teóricos escogidos desde el punto de vis- 
ta que pretende abordar, y desde ahí plante sus acuerdos o desacuerdos con la teoría. No en vano, cada uno de los autores de los textos del libro titula su escrito con de una manera que resalta las contribuciones teóricas a la realidad contemporánea.

Por lo anterior, se propone la siguiente división del texto, a manera ejemplificativa y enunciativa. Por un lado, como académicos que presentan una visión interna del derecho, se pueden incluir los nombres de Ronald Dworkin, Robert Alexy y Jeremy Waldron. Estos autores hablan de lo que es el derecho, sus fundamentos, $\mathrm{y}$, sobre todo, del rol de los jueces.

Primero, Ronald Dworkin es presentado por el autor del capítulo como un importante crítico del positivismo jurídico y uno de los autores más influyentes de la teoría jurídica angloamericana del siglo XX (p. 149). En concreto, el capítulo se centra en las discusiones del teórico sobre los debates entre libertad e igualdad, con especial énfasis en los deberes de obediencia a la ley. Además, muestra las reflexiones de Dworkin sobre la discrecionalidad judicial. De esta manera, el capítulo presenta tres conceptos básicos sobre este académico: el rechazo a la premisa mayoritaria, la tesis de los derechos y el derecho como integridad. El autor cierra señalando tres afinidades o coincidencias con lo estudiado: rechaza la premisa mayoritaria, favorece la unidad y la actualización del derecho a través de la tesis del derecho como integridad. A pesar de las afinidades, el autor identifica dos dificultades en la aplicación de la teoría de Dworkin a la práctica constitucional contemporánea: la tesis de los derechos de Dworkin se construye alrededor de unos derechos constitucionales que se limitan a las libertades clásicas y las dificultades que se presentan al ver a los derechos como límites categóricos en lugar de verlos como puntos de referencia para el diálogo.

Segundo, el autor del capítulo de Robert Alexy destaca la distinción entre casos fáciles y casos difíciles. Para resolver los casos difíciles Alexy ofrece una teoría completa del derecho; para esto, su trabajo ha intentado evidenciar las estrechas relaciones entre la teoría de la argumentación jurídica, la teoría de los derechos fundamentales y el concepto y validez del derecho. El autor propone una lectura de Alexy a través de las discusiones en la Corte Constitucional. De ahí, plantea los siguientes interrogantes: ¿qué tipo y cantidad de asuntos decidió definitivamente la Constitución? ¿Cuál es la estructura de las normas que conforman la Constitución? ¿Cuál es la relevancia de la proporcionalidad para definir el alcance de las normas con estructura de principio y el modo en que ellas se relacionan? En particular, el autor destaca la tarea de Alexy de elaborar una teoría de los principios, en especial, la teoría de la proporcionalidad (p. 237). Este teórico del derecho logró plantear una solución a un nudo al que se ven sometidos los jueces, más que todo el juez constitucional, que es el de ponderación de principios. Concluye el escritor del texto diciendo que Alexy logró una contribución en dirección a resolver el caso difícil de 
establecer cómo debe llevarse a cabo la ponderación sin que ninguno de los elementos del constitucionalismo -derechos, democracia y jurisdicción constitucional- pierdan su lugar.

Tercero, los autores que resumen las ideas de Jeremy Waldron hacen un recorrido desde sus nociones más tempranas hasta sus preocupaciones más recientes sobre dignidad humana. De acuerdo con este recorrido, los escritores del texto destacan algunas lecciones. En particular, se resalta el proyecto de Waldron de hacer contribuciones que implican a veces desafiar las concepciones heredadas. A partir de ello, el teórico ha iniciado proyectos ambiciosos como el de crear una teoría general del derecho. Además, Waldron ha sido conocido por su firme oposición al escrutinio judicial de las leyes (p. 316).

Estos teóricos, y otros presentes en el libro, se dedican a buscar postulados básicos del derecho en los que se fundamenta la teoría de la autoridad. En particular, desde la perspectiva interna de la disciplina, los académicos han contribuido a definir qué criterios interpretativos deben tener en cuenta los jueces para fallar, qué es un caso fácil o un caso difícil, cuáles son las potestades que deben tener los jueces constitucionales, entre otras. Así mismo, teóricos como Waldron han dejado en el contexto latinoamericano, en especial el colombiano, serias dudas acerca de la "mejor posición" de los magistrados de la Corte Constitucional para tomar decisiones que pueden considerarse como contramayoritarias.

Ahora bien, dentro de los académicos abordados que muestran una visión externa del derecho están Hannah Arendt, Catharine MacKinnon y Janet Halley. Estas autoras hablan acerca de las realidades que influyen en el derecho, en especial, en las decisiones que toman los jueces.

Primero, la autora del capítulo de Hannah Arendt señala que la mayor potencia de la teórica es su carácter de acontecimiento (p. 69). Sus escritos tienen un carácter expuesto a la singularidad de los eventos, es decir que son los eventos de la realidad los que los dotan de sentido y de inteligibilidad. En especial, los textos de Arendt están marcados por la experiencia del totalitarismo, para explicar las condiciones que condujeron a su consolidación. De ahí plantea sus críticas a las estructuras -no necesariamente totalitarias-como el principio de soberanía y el Estado-nación, y cómo estos pueden producir violencia. Para la autora, lo enriquecedor de esta académica es mostrar precisamente una postura productiva del derecho sin llegar a posturas totalizantes que acentúan la violencia (p. 86). En este sentido, Arendt muestra cómo el derecho puede crear pluralidad. Sin embargo, en su intento por separarse de ciertas posturas, hace una división tajante entre política de la necesidad y política de la violencia, en la que olvida que donde aparece el conflicto se genera un cambio en la vida social. 
Segundo, MacKinnon y Halley están dentro de las teóricas que plantean teorías feministas. De una parte, MacKinnon ha sido criticada por sus posturas calificadas como radicales (p. 240). En particular, la autora se concentra en los resultados prácticos de la teoría de la erotización de esta académica. Así, de manera concluyente afirma que el nuevo derecho es feminista y, por lo tanto, necesita de este movimiento para construir panoramas comunes a través de reflexiones empáticas y miradas diferenciales para construir un sentido de justicia que incluya a todos (p. 260).

De otra parte, la autora del capítulo que aborda a Halley se concentra en destacar la importancia de la categoría feminismo de la gobernanza para la teoría del derecho. Con esto, la autora quiere destacar el papel que el feminismo ha tenido en la producción de una reflexión respecto del derecho y sus impactos en lo jurídico. Según Halley, el feminismo de la gobernanza ilustra una variedad de poderes que se organizan en el contexto social y retan la noción de poder meramente estatal. Para la autora, el estudio de esta teórica sirve para entender la relación entre el proyecto de emancipación feminista y los dispositivos prescriptivos y normativos de conductas como el derecho. Así mismo, ayuda a identificar cuándo el feminismo se convierte en gobernanza, y las ventajas y desventajas de esta postura (p. 282). Esto permite a académicos y activistas ser conscientes del impacto que pueden generar sus intervenciones.

De acuerdo con lo anterior, estas teóricas, junto con otros del libro, más allá de postulados básicos del derecho, buscan mostrar la interacción que tienen el mundo jurídico, los movimientos sociales y las posturas políticas. Estos estudios, a su vez, ayudan a matizar e incorporar en las decisiones judiciales ideas externas a lo simplemente jurídico.

Finalmente, se destaca la enorme contribución que este libro hace a la teoría del derecho, pues efectivamente sus autores logran demostrar cómo los debates de la teoría y filosofía del derecho adquieren actualidad en nuestra práctica judicial. Así mismo, cómo las palabras de distintos teóricos del derecho pueden ayudar a resolver problemáticas que, lejos de ser novedosas, ya han sido identificadas y solucionadas muchos años atrás. Sin embargo, a manera de crítica constructiva, se quieren destacar dos puntos. El primero es que los autores escogidos para hacer parte del libro son todos del centro de Colombia, esto hace que se echen de menos otras perspectivas regionales, igualmente importantes si se quiere indagar acerca del cambio generado por la Constitución de 1991 en la teoría y filosofía del derecho. El segundo, es que dentro de los teóricos del derecho escogidos no está ninguno suramericano. Esta omisión podría crear dudas acerca de la producción teórica del derecho en esta parte del mundo, que ha mostrado ser igualmente valiosa que la generada en otras regiones. 